\title{
Clinical benefits of metformin in gynecologic oncology (Review)
}

\author{
ATSUSHI IMAI $^{1,2}$, SATOSHI ICHIGO $^{1}$, KAZUTOSHI MATSUNAMI $^{1}$, HIROSHI TAKAGI $^{1}$ and KEIGO YASUDA $^{3}$ \\ ${ }^{1}$ Department of Obstetrics and Gynecology; ${ }^{2}$ Institute of Endocrine-Related Cancer; \\ ${ }^{3}$ Department of Endocrinology and Internal Medicine, Matsunami General Hospital, Kasamatsu, Gifu 501-6062, Japan
}

Received August 26, 2014; Accepted May 20, 2015

DOI: $10.3892 / \mathrm{ol} .2015 .3262$

\begin{abstract}
Evidence has suggested that diabetes may contribute to the initiation and progression of specific types of cancer. Metformin, a biguanide, has become the preferred first-line therapy for the treatment of type 2 diabetes. Metformin is inexpensive, has a proven safety profile and is able to be safely combined with additional antidiabetic agents. In addition to the well-established antidiabetic effects of metformin, there has also been notable interest in its antitumor properties. The present review discusses the emerging role of metformin as an example of an existing drug, used worldwide in the treatment of diabetes, which has been demonstrated to exert significant in vitro and in vivo anticancer activities and has thus been investigated in clinical trials. In gynecologic oncology, metformin has been suggested to exhibit significant treatment efficacy against endometrial cancer. Three studies have demonstrated the potential therapeutic effects of metformin on the survival outcome of patients with ovarian cancer and in ovarian cancer prevention. However, this evidence was based on observational studies. Metformin has been shown to exert no statistically significant beneficial effect on cervical cancer incidence or mortality. By cancer site, the current limited insights highlight the need for clinical investigations and better-designed studies, along with evaluation of the effects of metformin on cancer at other sites.
\end{abstract}

\section{Contents}

1. Introduction

2. Metformin mechanism of action

3. Metformin and ovarian cancer

4. Metformin and cervical cancer

5. Metformin and endometrial cancer

6. Conclusion

Correspondence to: Dr Atsushi Imai, Institute of Endocrine-Related Cancer, Matsunami General Hospital, 185-1 Dendai, Kasamatsu, Gifu 501-6062, Japan

E-mail: aimai@matsunami-hsp.or.jp

Key words: endometrial cancer, cervical cancer, ovarian cancer, diabetes mellitus, insulin, metformin

\section{Introduction}

Emerging evidence from observational studies and meta-analyses has suggested that diabetes mellitus may be associated with an increased risk of cancer. An increase in site-specific cancer incidence associated with diabetes mellitus has also been described in a number of systemic reviews and meta-analyses (1-6). Although the mechanisms underlying this association are yet to be investigated, the most frequently proposed hypothesis is the effect of insulin resistance with secondary hyperinsulinemia, since insulin may exert mitogenic effects via the insulin-like growth factor-1 (IGF1) receptor (7-11). Furthermore, hyperglycemia itself may enhance carcinogenesis via the induction of oxidative stress (12-14).

Metformin, a biguanide frequently used in the treatment of type 2 diabetes, has been demonstrated to exert marked chemopreventative and antiproliferative effects against various types of cancer $(1,2,15-20)$. Metformin is able to inhibit cell growth via insulin and non-insulin dependent mechanisms (1,2,15-17), while enhancing insulin receptor sensitivity, increasing insulin uptake and therefore reducing systemic insulin levels. Metformin is also able to inhibit cell proliferation via activation of the growth inhibitory adenosine monophosphate-activated protein kinase (AMPK). AMPK blocks signaling via the phosphatidylinositol 3-kinase (PI3K)/Akt and mitogen-activated protein kinase (MAPK) pathways, downstream of the insulin and IGF1 receptors $(2,15,16)$.

The results of in vitro and in vivo studies (see Table I), have indicated that metformin may be able to inhibit cancer cell growth and reduce the cancer risk of certain solid tumors. The present review aimed to systematically evaluate available evidence regarding the association between metformin exposure and the risk of various types of cancer and cancer mortality, in the field of gynecologic oncology (Table I).

\section{Metformin mechanism of action}

Metformin suppresses hepatic gluconeogenesis, which results in decreased serum levels of glucose and insulin. AMPK is a cellular energy sensor located within the cytoplasm, which is involved in the regulation of metabolism within cells $(2,21-23)$. Metformin reduces adenosine triphosphate (ATP) production, resulting in an increased AMP:ATP ratio, which leads to activation of the liver kinase B1 (LKB1)-AMPK signaling pathway (2,21-23). LKB1 protein is the product of the LBK1 
Table I. Results of clinical and preclinical studies of metformin targeting gynecological cancer.

\begin{tabular}{llll}
\hline First author $($ year; ref no. & Cancer subtype & \multicolumn{1}{c}{ Clinical trials } & \multicolumn{1}{c}{ In vitro studies } \\
\hline Franciosi $(2013 ; 33)$ & Ovarian cancer & Potential therapeutic effects & \\
Home $(2010 ; 34)$ & & \\
Baur $(2010 ; 35)$ & & \\
Dilokthornsakul $(2013 ; 36)$ & & No effect & Proliferation inhibition effects \\
Erices $(2013 ; 37)$ & & \\
Rattan $(2011 ; 38)$ & & \\
Yasmeen $(2011 ; 39)$ & & Proliferation inhibition effects \\
Kim $(2014 ; 40)$ & Cervical cancer & No report & Proliferation inhibition effects \\
Xiao $(2012 ; 41)$ & Potential therapeutic effects & \\
Owen $(2000 ; 23)$ & Potential therapeutic effects & \\
Nevadunsky $(2014 ; 42)$ & & Potential therapeutic effects & \\
Currie $(2012 ; 47)$ & Potential therapeutic effects & \\
Ko $(2014 ; 48)$ & No effect & \\
Becker $(2013 ; 49)$ & Potential therapeutic effects & Proliferation inhibition effects \\
Cantrell $(2010 ; 50)$ & & Proliferation inhibition effects \\
Tan $(2012 ; 51)$ & & Proliferation inhibition effects \\
Hanna $(2012 ; 52)$ & & Proliferation inhibition effects \\
Shao et al $(2014 ; 55)$ & & Proliferation inhibition effects \\
Takahashi $(2014 ; 56)$ & & Proliferation inhibition effects \\
Sarfstein $(2013 ; 57)$ & & \\
Stevens $(2012 ; 61)$ & & \\
Zhang $(2014 ; 62)$ & & Proliferation inhibition effects & \\
Costello $(2007 ; 64)$ & & Proliferation inhibition effects & \\
\hline
\end{tabular}

tumor suppressor gene. LKB1 has been demonstrated to induce AMPK phosphorylation and AMPK-mediated signal transduction, while metformin inhibits hepatic gluconeogenesis in an LKB1- and AMPK-independent manner, by decreasing hepatic energy status (2,24-26). Additional studies have suggested that metformin may inhibit carcinogenesis and/or cancer cell growth via diverse pathways (15,27-29). Phosphorylation of the AMPK catalytic subunit occurs in the presence of LKB1, and is facilitated by AMP. Increasing intracellular levels of AMP therefore activates AMPK, which results in the inhibition of mammalian target of rapamycin (mTOR) signaling, downregulating liver gluconeogenesis.

Metformin exerts indirect (insulin-dependent) and direct (insulin-independent) effects at the cellular level. The direct effect of metformin is mediated by AMPK activation and reduction of the mTOR signaling pathway, which leads to inhibition of gluconeogenesis in the liver, protein synthesis and proliferation of cancer cells $(25,30-32)$. The indirect effects of metformin are mediated through its blood glucose lowering capabilities and subsequent reduction in circulating insulin levels.

Fig. 1 outlines the potential anticancerogenic effects of metformin. Metformin activates AMPK in the liver and skeletal muscles, thereby reducing gluconeogenesis in the liver and enhancing glucose uptake by the peripheral tissues, resulting in lower blood glucose and insulin levels $(2,15,16)$. Insulin has been found to exert mitogenic activity and thus may, theoretically, have a promotional effect on the growth of tumor cells.
Although various anticancer effects of metformin have previously been described $(1,2,15-20,24,25)$, the suppression of LKB1-mediated mTOR signaling is hypothesized to be the fundamental mechanism underlying these effects. Metformin has been demonstrated to be associated with reduced risk and enhanced overall survival rates of several obesity-associated types of cancer, although variable results have been obtained between studies.

\section{Metformin and ovarian cancer}

Three studies, comprising two randomized controlled trials $(33,34)$ and one observational study $(35)$, examined the association between the use of metformin and ovarian cancer. The results of these studies revealed potentially beneficial effects of metformin on the survival outcomes of ovarian cancer and in the prevention of ovarian cancer. However, the majority of this evidence is based on the results of observational studies. Further, well-conducted, controlled clinical trials are therefore required to verify the beneficial effects of metformin on ovarian cancer survival and prevention (36).

In vitro studies have revealed that metformin is able to enhance the effects of various chemotherapeutic treatment strategies by improving drug efficacy, and circumventing chemoresistance in epithelial ovarian cancer (30,37-39). Erices et al (37) demonstrated that no significant decrease in viability or alteration in the cell cycle was observed in ovarian cancer cell lines treated with micromolar concentrations 


\section{Metformin}

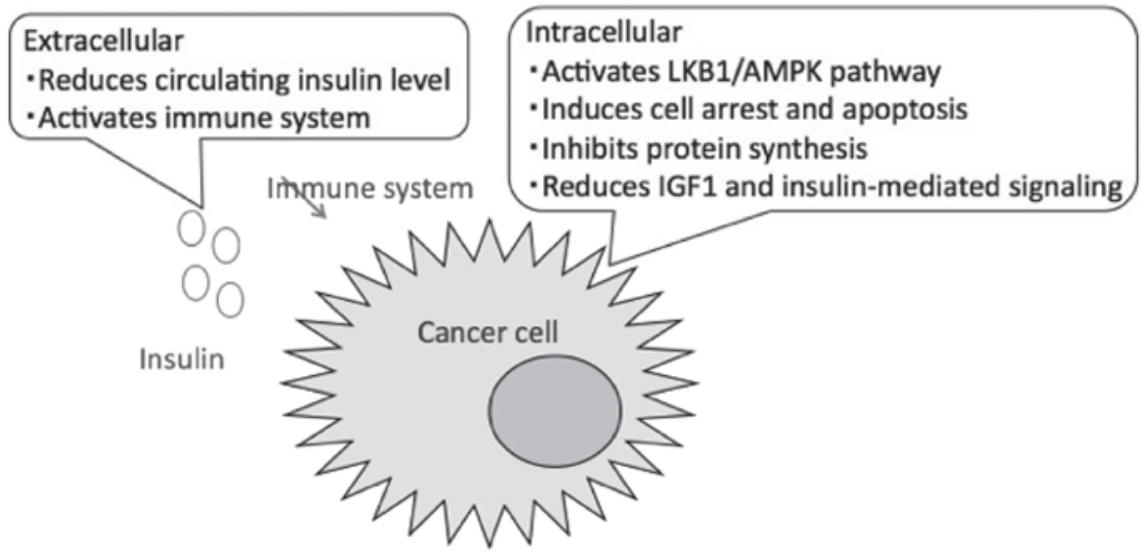

Figure 1. Proposed antitumor effects of metformin. AMPK, adenosine monophosphate kinase; LKB1, liver kinase B1; IGF1, insulin-like growth factor 1.

of metformin alone; however, significant cytotoxicity was observed following treatment with micromolar metformin in combination with chemotherapy, at concentrations where chemotherapy alone induced no loss of cell viability. The specific mechanism underlying the synergistic effect of metformin and chemotherapy remains to be fully elucidated. One potential explanation is that metformin may be selectively toxic to the ovarian cancer stem cell, which is considered to be the cause of chemoresistance (40).

\section{Metformin and cervical cancer}

To date, there have been few studies or clinical trials investigating the potential use of metformin for the treatment of cervical cancer. Due to the mechanisms by which metformin is suggested to induce tumor suppression, it is likely able to attenuate the growth of cancer in multiple systems, including cervical cancer. One study, using an in vivo cell culture system, demonstrated that metformin inhibited the growth of certain cervical cancer cells by stimulating apoptosis and autophagy (41). The metformin-sensitive cells expressed LKB1 at normal levels and exerted an AMPK-mTOR signaling response following metformin application. Therefore, metformin may augment LKB1 tumor suppressive effects, inhibit cell growth and decrease tumor cell viability via activation of LKB1-AMPK signaling in cervical cancer.

\section{Metformin and endometrial cancer}

Obesity is a major risk factor for endometrial cancer; therefore, the incidence of endometrial cancer has been predicted to increase as a consequence of the obesity epidemic, which may also worsen endometrial cancer outcomes $(42,43)$. However, the association between endometrial cancer and obesity varies according to disease histology. Obesity exhibits a greater association with the risk of endometrioid (type 1) endometrial cancer, than non-endometrioid (type 2) endometrial cancer (44). Data from multiple studies has indicated that the obesity-endometrial cancer association occurs as a result of the higher average circulating insulin and estradiol levels detected in obese females, and that this effect is specific to endometrioid tumors $(42,45,46)$.

There are a number of clinical studies regarding the effect of metformin on endometrial cancer outcomes. In one population-based study, diabetic women diagnosed with ovarian or endometrial cancer who were being treated with metformin at the time of diagnosis exhibited half the risk of mortality (of any cause) than that of the non metformin-treated patients [hazard ratio, 0.48; 95\% confidence interval (CI), 0.28-0.81] (47). However, these results do not consider cancer pathology, stage or treatment strategy, which are significant factors, given the biological heterogeneity of endometrial cancer subtypes. Another retrospective study reported improved overall survival rates among diabetic patients on metformin with non-endometrioid type cancer, compared with that of non-metformin users and non-diabetic patients; however, cancer specific recurrence or progression were not reported (42). In a multi-institutional retrospective cohort analysis, the effects of metformin use on treatment-associated outcomes of endometrial cancer were evaluated using univariate and multivariate modeling (48). Metformin use was associated with improved recurrence-free survival (RFS) and overall survival (OS) but not time to recurrence (TTR). The role of metformin in the modification of cancer recurrence remains elusive.

A case-control analysis study investigated the association between the use of various antidiabetic drugs, including metformin, and the risk of endometrial cancer, using the United Kingdom-based General Practice Research Database (49). In total, 2,554 cases exhibiting endometrial cancer and 15,324 matched controls were identified. The risk of endometrial cancer was not found to differ between patients what had ever used metformin and those who had never used metformin [adjusted (adj.) odds ration (OR), 0.86; 95\% CI, 0.63-1.18)]. Following stratification by duration of exposure, long-term ( $\geq 25$ prescriptions) use of metformin (adj. OR, 0.79; 95\% CI, 0.54-1.17), sulfonylureas (adj. OR, 0.96; 95\% CI, 0.65-1.44), thiazolidinediones ( $\geq 15$ prescriptions; adj. OR, 1.22; 95\% CI, 0.67-2.21) or insulin (adj. OR, 1.05; 95\% CI, $0.79-1.82$ ) were not found to be significantly associated with the risk of endometrial cancer. 
In vitro cell system analyses have demonstrated that metformin: i) inhibits the growth of various endometrial cancer cell lines; ii) attenuates the invasion and metastasis of endometrial cancer cell lines by modifying the nuclear factor- $\mathrm{\kappa B}$, matrix metalloproteinase-2/9/Akt and Erk $_{1 / 2}$ pathways; and iii) enhances endometrial cancer cell chemosensitivity to cisplatin and paclitaxel by reducing glyoxalase I expression and regulating the mTOR signaling pathway $(23,50-52)$. At the molecular level, the fundamental activity of metformin inhibits mitochondrial oxidative phosphorylation, and may exert energy-associated stress on neoplastic cells (23). This inhibition of oxidative phosphorylation reduces the production of ATP, activating the cellular energy regulator AMPK and its downstream effectors, including mTOR (53). At the whole-organism level, the antiproliferative effects of metformin may be attributed to the decrease in circulating insulin levels induced by the reduced hepatic gluconeogenesis characteristic of insulin-responsive tumors (54). Metformin potently inhibits growth in a dose-dependent manner in endometrial cancer cell lines. Metformin resulted in G1 phase cell cycle arrest, induction of apoptosis and decreased human telomerase reverse transcriptase expression in endometrial cancer cells $(50,55)$. Treatment with metformin attenuates the estrogen-dependent proliferative expression of c-myc and c-fos in the obese rat endometrium, an effect which was accompanied by inhibition of the phosphorylation of insulin and IGF1 receptors, as well as $\operatorname{Erk}_{1 / 2}(17,55)$. In vitro studies have indicated that metformin inhibits rat endometrial cell line proliferation and suppresses endometrial cancer cell growth via cell cycle arrest and concomitant autophagy and apoptosis $(55,56)$.

Regarding non-endometrioid endometrial cancer, diabetic endometrial cancer patients with non-endometrioid tumors who were taking metformin were demonstrated to have a lower risk of mortality than that of patients with endometrial cancer who did not use metformin (42). Metformin may therefore function as an adjuvant therapy for the treatment of non-endometrioid endometrial cancer. Investigating uterine serous carcinoma, an aggressive subtype of endometrial cancer, Sarfstein et al (57) demonstrated that metformin interacted with the IGF pathway, inducing apoptosis and inhibition of proliferation and migration of uterine serous carcinoma cell lines with wild-type or mutant $\mathrm{p} 53$.

\section{Conclusion}

The anticancer effects of metformin discussed in the present review indicate the possibility that certain diabetes-associated types of cancer may be circumvented. AMPK-dependent and -independent pathways have been suggested to underlie the anticancer effects of metformin treatment. The results of in vitro and in vivo studies have indicated that metformin may perturb cancer cell growth and reduce the cancer risk of certain solid tumors. Numerous clinical trials have suggested positive effects of metformin on pathological complete responses to neoadjuvant chemotherapy in diabetic patients with endometrial cancer, which suggest that metformin may augment the efficacy of chemotherapeutic treatment of endometrial cancer.

Metformin is a safe, low-cost drug, and therefore remains one of the most commonly prescribed drugs worldwide (6). In the majority of observational studies, the beneficial effect of metformin in the reduction of cancer risk was evident when the drug was used for $>5$ years $(15,58-61)$. However, existing evidence is not sufficient to support the anticancer effect of metformin on malignancies other than endometrial cancer. Long-term randomized clinical trials specifically designed to determine the effects of metformin on cancer risk are required in order to evaluate the hypothesis that metformin has an anticancer effect.

\section{References}

1. Noto H, Goto A, Tsujimoto T, Osame K and Noda M: Latest insights into the risk of cancer in diabetes. J Diabetes Investig 4: 225-232, 2013.

2. Sen S, He Y, Koya D and Kanasaki K: Cancer biology in diabetes. J Diabetes Investig 5: 251-264, 2014.

3. Srokowski TP, Fang S, Hortobagyi GN and Giordano SH: Impact of diabetes mellitus on complications and outcomes of adjuvant chemotherapy in older patients with breast cancer. J Clin Oncol 27: 2170-2176, 2009.

4. Chodick G, Heymann AD, Rosenmann L, Green MS, Flash S, Porath A, Kokia E and Shalev V: Diabetes and risk of incident cancer: A large population-based cohort study in Israel. Cancer Causes Control 21: 879-887, 2010.

5. Noto H, Tsujimoto T and Noda M: Significantly increased risk of cancer in diabetes mellitus patients: A meta-analysis of epidemiological evidence in Asians and non-Asians. J Diabetes Investig 2: 24-33, 2012.

6. Suissa S and Azoulay L: Metformin and cancer: Mounting evidence against an association. Diabetes Care 37: 1786-1788, 2014.

7. Hemkens LG, Grouven U, Bender R, Günster C, Gutschmidt S, Selke GW and Sawicki PT: Risk of malignancies in patients with diabetes treated with human insulin or insulin analogues: A cohort study. Diabetologia 52: 1732-1744, 2009.

8. Mannucci E, Monami M, Balzi D, Cresci B, Pala L, Melani C, Lamanna C, Bracali I, Bigiarini M, Barchielli A, et al: Doses of insulin and its analogues and cancer occurrence in insulin-treated type 2 diabetic patients. Diabetes Care 33: 1997-2003, 2010.

9. Lind M, Fahlén M, Eliasson B and Odén A: The relationship between the exposure time of insulin glargine and risk of breast and prostate cancer: An observational study of the time-dependent effects of antidiabetic treatments in patients with diabetes. Prim Care Diabetes 6: 53-59, 2012.

10. Weinstein D, Simon M, Yehezkel E, Laron Z and Werner H: Insulin analogues display IGF1-like mitogenic and anti-apoptotic activities in cultured cancer cells. Diabetes Metab Res Rev 25: 41-49, 2009.

11. Ljung R, Talbäck M, Haglund B, Jonasson JM, Gudbjörnsdòttir S and Steineck G: Insulin glargine use and short-term incidence of malignancies - a three-year population-based observation. Acta Oncol 50: 685-693, 2011.

12. Barclay AW, Petocz P, McMillan-Price J, Flood VM, Prvan T, Mitchell P and Brand-Miller JC: Glycemic index, glycemic load and chronic disease risk - a meta-analysis of observational studies. Am J Clin Nutr 87: 627-637, 2008.

13. Stocks T, Rapp K, Bjørge T, Manjer J, Ulmer H, Selmer R, Lukanova A, Johansen D, Concin H, Tretli S, et al: Blood glucose and risk of incident and fatal cancer in the metabolic syndrome and cancer project (me-can): Analysis of six prospective cohorts. PLoS Med 6: e1000201, 2009.

14. Abe R and Yamagishi S: AGE-RAGE system and carcinogenesis. Curr Pharm Des 14: 940-945, 2008.

15. Malek M, Aghili R, Emami Z and Khamseh M: Risk of cancer in diabetes: The effect of metformin. ISRN Endocrinol 2013: 636927, 2013.

16. Pulito C, Sanli T, Rana P, Muti P, Blandino G and Strano S: Metformin: On ongoing journey across diabetes, cancer therapy and prevention. Metabolites 3: 1051-1075, 2013.

17. Zhang Q, Celestino J, Schmandt R, McCampbell AS, Urbauer DL, Meyer LA, Burzawa JK, Huang M, Yates MS, Iglesias D, et al: Chemopreventive effects of metformin on obesity-associated endometrial proliferation. Am J Obstet Gynecol 209: e1-e24, 2013.

18. Del Barco S, Vazquez-Martin A, Cufí S, Oliveras-Ferraros C, Bosch-Barrera J, Joven J, Martin-Castillo B and Menendez JA: Metformin: Multi-faceted protection against cancer. Oncotarget 2: 896-917, 2011. 
19. Dowling RJ, Goodwin PJ and Stambolic V: Understanding the benefit of metformin use in cancer treatment. BMC Med 9: 33, 2011.

20. Engelman JA and Cantley LC: Chemoprevention meets glucose control. Cancer Prev Res (Phila) 3: 1049-1052, 2010.

21. Fogarty S and Hardie DG: Development of protein kinase activators: AMPK as a target in metabolic disorders and cancer. Biochim Biophys Acta 1804: 581-591, 2010.

22. Kubota T: Update in polycystic ovary syndrome: New criteria of diagnosis and treatment in Japan. Reprod Med Biol 12: 71-77, 2013.

23. Owen MR, Doran E and Halestrap AP: Evidence that metformin exerts its anti-diabetic effects through inhibition of complex 1 of the mitochondrial respiratory chain. Biochem J 348: 607-614, 2000

24. Foretz M, Hébrard S, Leclerc J, Zarrinpashneh E, Soty M, Mithieux G, Sakamoto K, Andreelli F and Viollet B: Metformin inhibits hepatic gluconeogenesis in mice independently of the LKB1/AMPK pathway via a decrease in hepatic energy state. J Clin Invest 120: 2355-2369, 2010.

25. Dowling RJ,Zakikhani M,Fantus IG, Pollak M and Sonenberg N: Metformin inhibits mammalian target of rapamycin-dependent translation initiation in breast cancer cells. Cancer Res 67: 10804-10812, 2007

26. Shackelford DB and Shaw RJ: The LKB1-AMPK pathway: Metabolism and growth control in tumour suppression. Nat Rev Cancer 9: 563-575, 2009 .

27. Kalender A, Selvaraj A, Kim SY, Gulati P, Brûlé S, Viollet B, Kemp BE, Bardeesy N, Dennis P, Schlager JJ, et al: Metformin, independent of AMPK, inhibits mTORC1 in a rag GTPase-dependent manner. Cell Metab 11: 390-401,2010.

28. Saeedi R, Parsons HL, Wambolt RB, Paulson K, Sharma V, Dyck JR Brownsey RW and Allard MF: Metabolic actions of metformin in the heart can occur by AMPK-independent mechanisms. Am J Physiol Heart Circ Physiol 294: H2497-H2506, 2008.

29. Treins C, Murdaca J, Van Obberghen E and Giorgetti-Peraldi S: AMPK activation inhibits the expression of HIF-1alpha induced by insulin and IGF-1. Biochem Biophys Res Commun 342: 1197-1202, 2006.

30. Gotlieb WH, Saumet J, Beauchamp MC, Gu J, Lau S, Pollak MN and Bruchim I: In vitro metformin anti-neoplastic activity in epithelial ovarian cancer. Gynecol Oncol 110: 246-250, 2008

31. Zakikhani M, Dowling R, Fantus IG, Sonenberg N and Pollak M: Metformin is an AMP kinase-dependent growth inhibitor for breast cancer cells. Cancer Res 66: 10269-10273, 2006.

32. Alimova I, Liu B, Fan Z, Edgerton SM, Dillon T, Lind SE and Thor AD: Metformin inhibits breast cancer cell growth, colony formation and induces cell cycle arrest in vitro. Cell Cycle 8: 909-915, 2009

33. Franciosi M, Lucisano G, Lapice E, Strippoli G, Pellegrini F and Nicolucci A: Metformin therapy and risk of cancer in patients with type 2 diabetes: Systematic review. PLoS One 8: e71583, 2013.

34. Home PD, Kahn SE, Jones NP, Noronha D, Beck-Nielsen H and Viberti G; ADOPT Study Group and RECORD Steering Committee: Experience of malignancies with oral glucose-lowering drugs in the randomised controlled ADOPT (A Diabetes Outcome Progression Trial) and RECORD (Rosiglitazone Evaluated for Cardiovascular Outcomes and Regulation of Glycaemia in Diabetes) clinical trials. Diabetologia 53: 1838-1845, 2010.

35. Baur DM, Klotsche J, Hamnvik OP, Sievers C, Pieper L, Wittchen HU, Stalla GK, Schmid RM, Kales SN and Mantzoros CS: Type 2 diabetes mellitus and medications for type 2 diabetes mellitus are associated with risk for and mortality from cancer in a German primary care cohort. Metabolism 60 : $1363-1371,2010$

36. Dilokthornsakul P, Chaiyakunapruk N, Termrungruanglert W, Pratoomsoot C, Saokeaw S and Sruamsiri R: The effects of metformin on ovarian cancer: A systematic review. Int J Gynecol Cancer 23: 1544-1551, 2013.

37. Erices R, Bravo M, Gonzalez P, Oliva B, Racordon D, Garrido M, Ibañez C, Kato S, Brañes J, Pizarro J, et al: Metformin, at concentrations corresponding to the treatment of diabetes, potentiates the cytotoxic effects of carboplatin in cultures of ovarian cancer cells. Reprod Sci 20: 1433-1446, 2013.

38. Rattan R, Graham RP, Maguire JL, Giri S and Shridhar V: Metformin suppresses ovarian cancer growth and metastasis with enhancement of cisplatin cytotoxicity in vivo. Neoplasia 13 : 483-491, 2011.

39. Yasmeen A, Beauchamp MC, Piura E, Segal E, Pollak M and Gotlieb WH: Induction of apoptosis by metformin in epithelial ovarian cancer: Involvement of the BCL-2 family proteins. Gynecol Oncol 121: 492-498, 2011.
40. Kim TH, Suh DH, Kim MK and Song YS: Metformin against cancer stem cells through the modulation of energy metabolism: Special considerations on ovarian cancer. Biomed Res Int 2014 132702,2014

41. Xiao X, He Q, Lu C, Werle KD, Zhao RX, Chen J, Davis BC, Cui R, Liang J and Xu ZX: Metformin impairs the growth of liver kinase B1-intact cervical cancer cells. Gynecol Oncol 127: 249-255, 2012

42. Nevadunsky NS, Van Arsdale A, Strickler HD, Moadel A, Kaur G, Frimer M, Conroy E, Goldberg GL and Einstein MH: Metformin use and endometrial cancer survival. Gynecol Oncol 132: 236-240, 2014

43. Siegal R, Ward E, Browley O and Jemal A: Cancer statistics, 2011: The impact of eliminating socioeconomic and racial disparities on premature cancer deaths. CA Cancer J Clin 61: 212-236, 2011

44. Fader AN, Arriba LN, Frasure HE and Von Gruenigen VE: Endometrial cancer and obesity: Epidemiology, biomarkers, prevention and survivorship. Gynecol Oncol 114: 121-127, 2009.

45. Gunter M, Hoover D, Yu H, Wassertheil-Smoller S, Manson J, Li J, Harris T, Rohan T, Xue X, Ho G, et al: A prospective evaluation of insulin and insulin-like growth factor-I as risk factors for endometrial cancer. Cancer Epidemiol Biomarkers Prev 17: 921-929, 929

46. Friberg E, Orsini N, Mantzoros CS and Wolk A: Diabetes mellitus and risk of endometrial cancer: A meta-analysis. Diabetologia 50: 1365-1374, 2007

47. Currie CJ, Poole CD, Jenkins-Jones S, Gale EA, Johnson JA and Morgan CL: Mortality after incident cancer in people with and without type 2 diabetes: Impact of metformin on survival. Diabetes Care 35: 299-304, 2012.

48. Ko E, Walter P, Jackson A, Clark L, Franasiak J, Bolac C, Havrilesky LJ, Secord AA, Moore DT, Gehrig PA and Bae-Jump V: Metformin is associated with improved survival in endometrial cancer. Gynecol Oncol 132: 438-442, 2014.

49. Becker C, Jick SS, Meier CR and Bodmer M: Metformin and the risk of endometrial cancer: A case-control analysis. Gynecol Oncol 129: 565-569, 2013.

50. Cantrell LA, Zhou C, Mendivil A, Malloy KM, Gehrig PA and Bae-Jump VL: Metformin is a potent inhibitor of endometrial cancer cell proliferation - implications for a novel treatment strategy. Gynecol Oncol 116: 92-98, 2010.

51. Tan B, Adya R, Chen J, Lehnert H, Saint Cassia LJ and Randeva HS: Metformin treatment exerts antiinvasive and antimetastatic effects in human endometrial carcinoma cells. J Clin Endocrinol Metab 96: 808-816, 2012.

52. Hanna RK, Zhou C, Malloy KM, Sun L, Zhong Y, Gehrig PA and Bae-Jump VL: Metformin potentiates the effects of paclitaxel in endometrial cancer cells through inhibition of cell proliferation and modulation of the mTOR pathway. Gynecol Oncol 125 : 458-469, 2012.

53. Hardie DG, Ross FA and Hawley SA: AMPK: A nutrient and energy sensor that maintains energy homeostasis. Nat Rev Mol Cell Biol 13: 251-262, 2012

54. Pollak M: The insulin and insulin-like growth factor receptor family in neoplasia: An update. Nat Rev Cancer 12: 159-169, 2012

55. Shao R, Li X, Feng Y, Lin JF and Billig H: Direct effects of metformin in the endometrium: A hypothetical mechanism for the treatment of women with PCOS and endometrial carcinoma. J Exp Clin Cancer Res 33: 41, 2014.

56. Takahashi A, Kimura F, Yamanaka A, Takebayashi A, Kita N, Takahashi K and Murakami T: Metformin impairs growth of endometrial cancer cells via cell cycle arrest and concomitant autophagy and apoptosis. Cancer Cell Int 14: 53, 2014.

57. Sarfstein R, Friedman Y, Attias-Geva Z, Fishman A, Bruchim I and Werner H: Metformin downregulates the insulin/IGF1 signaling pathway and inhibits different uterine serous carcinoma (USC) cells proliferation and migration in p53-dependent or -independent manners. PLoS One 8: e61537, 2013.

58. Decensi A, Puntoni M, Goodwin P, Cazzaniga M, Gennari A, Bonanni B and Gandini S: Metformin and cancer risk in diabetic patients: A systematic review and meta-analysis. Cancer Prey Res (Phila) 3: 1451-1461, 2010.

59. Bowker SL, Majumdar SR, Veugelers P and Johnson JA Increased cancer-related mortality for patients with type 2 diabetes who use sulfonylureas or insulin. Diabetes Care 29: 254-258, 2006

60. Libby G, Donnelly LA, Donnan PT, Alessi DR, Morris AD and Evans JM: New users of metformin are at low risk of incident cancer: A cohort study among people with type 2 diabetes. Diabetes Care 32: 1620-1625, 2009. 
61. Stevens RJ, Ali R, Bankhead CR, Bethel MA, Cairns BJ, Camisasca RP, Crowe FL, Farmer AJ, Harrison S, Hirst J, et al: Cancer outcomes and all-cause mortality in adults allocated to metformin: Systematic review and collaborative meta-analysis of randomised clinical trials. Diabetologia 55: 2593-2603, 2012.

62. Zhang ZJ and Li S: The prognostic value of metformin for cancer patients with concurrent diabetes: A systematic review and meta-analysis. Diabetes Obes Metab 16: 707-710, 2014.
63. Costello M, Shrestha B, Eden J, Johnson NP and Sjoblom P: Metformin versus oral contraceptive pill in polycystic ovary syndrome: A cochrane review. Hum Reprod 22: 1200-1209, 2007.

64. Costello M, Shrestha B, Eden J, Sjoblom P and Johnson N Insulin-sensitising drugs versus the combined oral contraceptive pill for hirsutism, acne and risk of diabetes, cardiovascular disease and endometrial cancer in polycystic ovary syndrome. Cochrane Database Syst Rev 24: CD005552, 2007. 